\title{
PEMANFAATAN LIMBAH KAYU UNTUK KEMASAN CENDERAMATA KHAS KALIMANTAN TIMUR
}

\author{
Dyan Asdar Nursapitri Dewi \\ Jurusan Desain Produk, Fakultas Teknik Sipil dan Perencanaan \\ Institut Teknologi Adhi Tama Surabaya \\ Jl. Arief Rahman Hakim 100, Surabaya, 60117 \\ e-mail : dhyan_nursafitiri@yahoo.co.id \\ Moch Junaidi Hidayat \\ Jurusan Desain Produk, Fakultas Teknik Sipil dan Perencanaan \\ Institut Teknologi Adhi Tama Surabaya \\ Jl. Arief Rahman Hakim 100, Surabaya, 60117 \\ e-mail : junaidi.despro@itats.ac.id
}

\begin{abstract}
ABSTRAK
Limbah kayu adalah sisa potongan kayu hasil dari proses produksi, yang pada saat ini belum dimanfaatkan semaksimal mungkin. Salah satunya di Kalimantan Timur, limbah kayu biasanya digunaka sebagai bahan bakar atau dibuang begitu saja. Metode yang digunakan dalam penelitian ini adalah menggunakan metode eksperimen, yang mengolah limbah sisa potongan menjadi sebuah produk. Hasil dari analisis eksperimen didapatkan bahwa limbah sisa potongan kayu tersebut dapat dijadikan sebagai bahan dalam pembuatan kemasan cenderamata khas Kalimantan Timur. Tahapan yang dilakukan diantaranya melewati proses pemilahan kondisi kayu, pembentukan pola, penghalusan, dan penggabungan pola, setelah itu dapat dilanjutkan ke dalam tahapan proses produksi kemasan dengan menerapkan konsep Etnik Simplicity yaitu perpaduan unsur budaya yang terkesan simpel dan eksklusif dengan tampilan visual sesuai gaya etnik yang dipilih. Dari hasil perancangan terdapat sepuluh desain alternatif, dan lima desain yang terpilih untuk final desain kemasan cenderamata yaitu kemasan untuk kalung, gelang, cincin, sarung dan kain yang nantinya dibuat menjadi sebuah produk kemasan untuk mengemas cenderamata khas Kalimantan Timur tersebut.
\end{abstract}

Kata Kunci : Kemasan, Cinderamata Kalimantan Timur, Limbah Kayu 
Dyan Asdar Nursapitri Dewi, Moch Junaidi Hidayat, Pemanfaatan Limbah Kayu Untuk Kemasan Cenderamata Khas Kalimantan Timur

Abstract

Wood waste is the remnants of wood produced from the production process, which at present has not been utilized as much as possible. One of them in East Kalimantan, wood waste is usually used as fuel or thrown away. The method used in this study is to use the experimental method, which treats the remaining waste into a product. The results of the experimental analysis found that the remaining wood waste can be used as material in making typical East Kalimantan souvenirs. The stages carried out include going through the process of sorting wood conditions, pattern formation, refinement, and merging patterns, after that it can be continued into the packaging production process by applying the Ethnic Simplicity concept, which is a combination of cultural elements that seem simple and exclusive with a visual appearance in accordance selected. From the results of the design there are ten alternative designs, and five designs chosen for the final design of souvenir packaging, namely packaging for necklaces, bracelets, rings, sarongs and fabrics which will later be made into a packaging product to package the typical East Kalimantan souvenir.

Keyword : Packaging, East Kalimantan Souvenir, Wood Waste

\section{PENDAHULUAN}

Penelitian ini memusatkan pada industri perkayuan yang berada di Kalimantan Timur, pemanfaatan limbah kayu yang ada saat ini masih kurang maksimal dikarenakan limbah kayu yang hanya digunakan sebagai bahan pembakaran dan dibuang begitu saja. Semakin banyaknya permintaan akan kebutuhan kayu, akan mengakibatkan meningkatnya pasokan bahan baku di industri perkayuan sehingga nantinya akan menghasilkan limbah kayu yang semakin banyak juga.

Salah satu jenis limbah kayu yang dihasilkan oleh bekas palet impor atau limbah dari hasil peti kemas yaitu kayu Jati Belanda atau kayu jati Londo. Biasanya material ini banyak digunakan kembali sebagai produk furniture dan produk-produk dekorasi sehingga menghasilkan limbah dari hasil produksi tersebut. Kayu jati belanda memiliki karakter tersendiri, karena serat kayu yang indah dan sangat menonjol motifnya dibanding kayu-kayu jenis lain, Jenis kayu ini juga tahan dari serangga rayap karena getahnya tidak disukai serangga. Pemanfaatan limbah kayu jati belanda hingga saat ini digunakan sebagai stand berjualan dan aksen interior, akan tetapi hingga saat ini belum dikembangkan sebagai bahan kemasan sebuah produk.

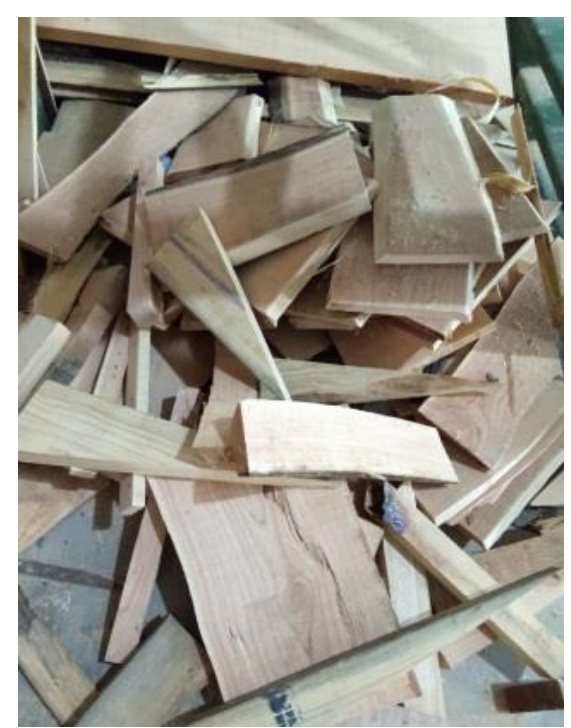

Gambar 1

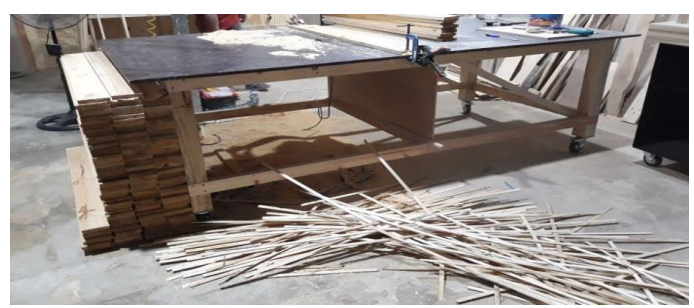

Gambar 2

Gambar 1, 2. Limbah Sisa Produksi Jati

Belanda Samarinda

(Sumber: Dokumen Dian Asdar , 20 Juni

2018) 
Vol. 6, No. 2, April 2019

Di Propinsi Kalimantan Timur yang memiliki beberapa suku budaya yang beragam dan dikenal dengan penduduk lokal suku dayak dengan berbagai keunikan dan ciri khas budayanya. Suku dayak menghasilkan kerajinan cendramata seperti kain tenun, kalung, gelang, topi, baju adat dan pernak-pernik lainnya yang kemudian dipasarkan diberbagai toko cenderamata khas Kalimantan Timur terutama. Hingga saat ini masih banyak produk cenderamata yang dikemas hanya menggunakan plastik bahkan tidak memiliki kemasan sama sekali. dapat disimpulkan bahwa pemanfaatan limbah kayu tersebut tidak dimanfaatkan semaksimal mungkin karena pada studi kasus limbah kayu hanya digunakan sebagai bahan pembakaran atau dibuang begitu saja, agar limbah tersebut dapat memiliki nilai jual yang tinggi maka dari itu bahan yang berasal dari limbah kayu tersebut akan dibuat menjadi produk kemasan cenderamata khas Kalimantan Timur. Limbah kayu yang akan digunakan sebagai bahan material utama dalam penelitian ini adalah limbah yang paling banyak ditemukan dari hasil proses industri, salah satunya limbah Jati Belanda karena memiliki tekstur seratnya yang khas menjadikan poin utama sebagai daya tarik yang dapat diekspos, penelitian ini dilakukan bertujuan agar dengan adanya kemasan yang berbahan limbah kayu yang didesain dengan unik dan menampilkan unsur khas dari Kalimantan Timur akan menambah daya tarik pengunjung untuk membeli produk tersebut.

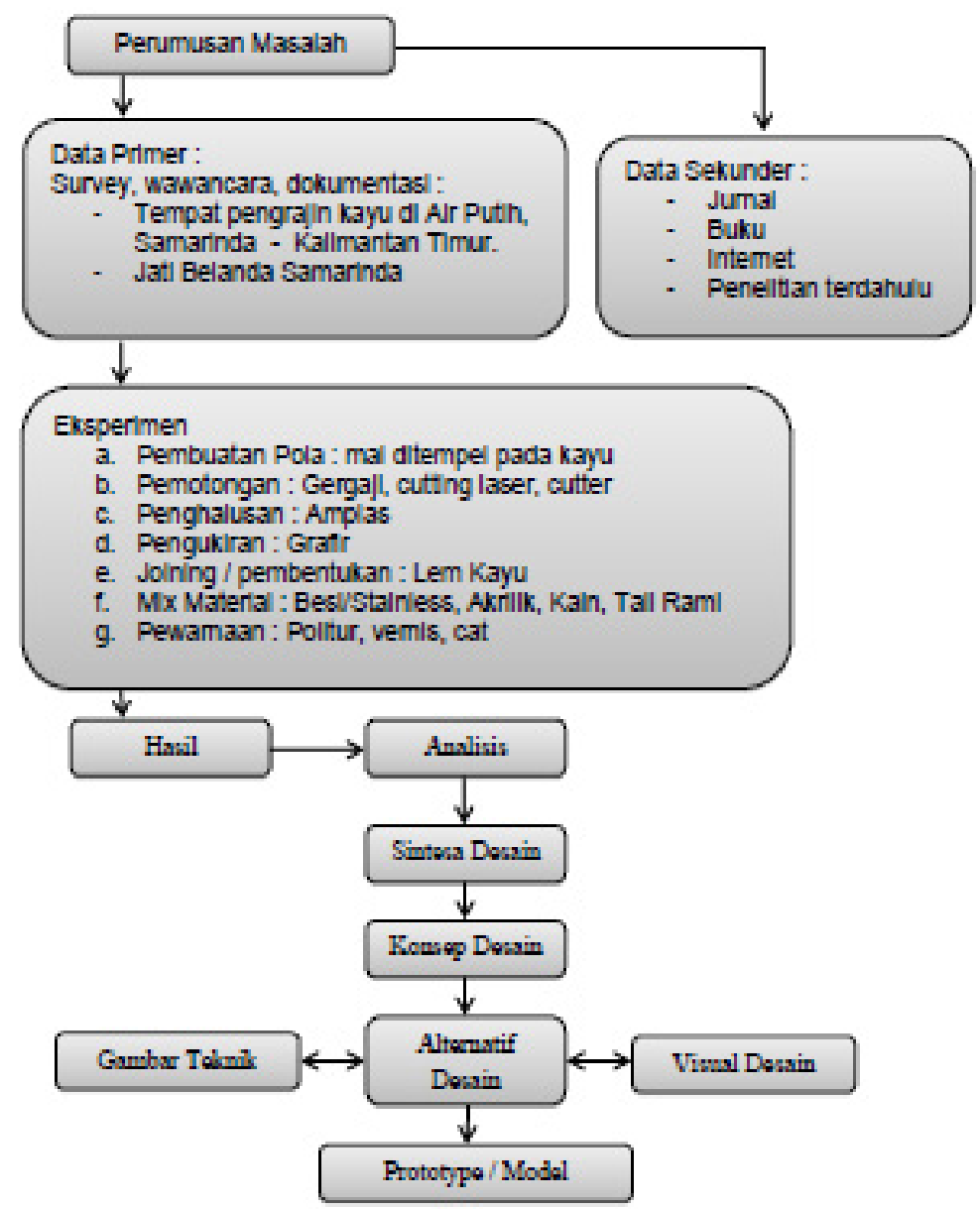

Gambar 3. Metodologi Desain 
Dyan Asdar Nursapitri Dewi, Moch Junaidi Hidayat, Pemanfaatan Limbah Kayu Untuk Kemasan Cenderamata Khas Kalimantan Timur

\section{METODE PENELITIAN}

Penelitian ini menggunakan penelitian jenis eksperimen, yaitu melakukan berbagai macam cara pengolahan setiap limbah kayu hingga menjadi bahan material untuk pembuatan sebuah produk berupa kemasan yaitu mulai dari pengeringan, pemotongan, pembentukan, penghalusan, hingga proses finishing yaitu pewarnaan limbah kayu. Peneliti mencoba menggambarkan alur penelitian dalam memecahkan masalah didalam metodologi desain, seperti yang tergambar dalam gambar 3 .

\section{TINJAUAN PUSTAKA}

\section{a. Motif}

Motif dayak pada dasarnya merupakan kombinasi antara suatu pola dasar yang mempunyai makna masing-masing, kemudian di kreasikan dalam berbagai perpaduan beberapa motif dasar sehingga menjadi satu kesatuan dengan rangkaian makna yang berarti. Sebenarnya motif dayak memiliki ciri khas yang hampir sama di seluruh wilayah Kalimantan. Baik itu Kalimantan Timur, Kalimantan Utara, Kalimantan Barat, Kalimantan Selatan, Kalimantan Barat, dan Kalimantan Tengah. (https://sahabatnesia. com/, Diakses 03 Mei 2018).

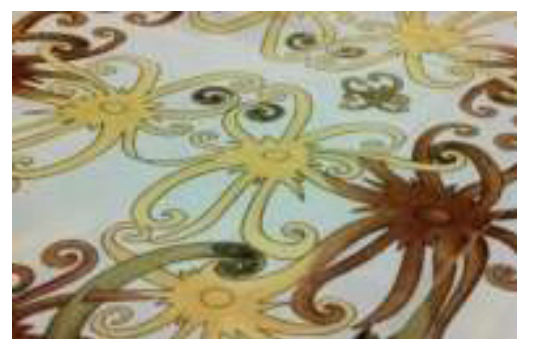

Gambar 4

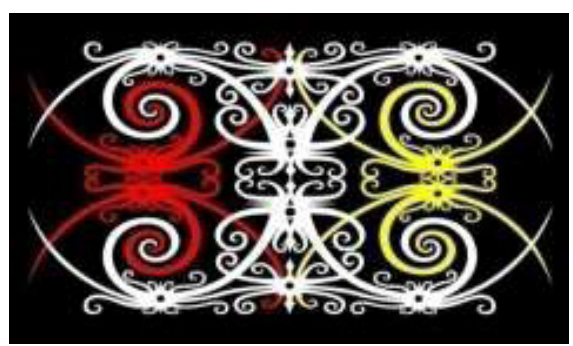

Gambar 5
Gambar 4, 5.

(Sumber : https://media.neliti.com/media/ publications/191767-ID-motif-dayak.pdf,

Diakses 04 Mei 2018)

Motif ini memiliki makna mengenai keabadian hidup. Penciptaan Motif ini terinspirasi dari tumbuhan Pakis (Polystichum setiferum). Bentuk motif ini berkeluk-keluk atau meliuk-liuk seperti halnya tumbuhan Pakis.

\section{b. Kemasan}

Kemasan dapat didefinisikan sebagai seluruh kegiatan merancang dan memproduksi wadah atau bungkus atau kemasan suatu produk. Kemasan meliputi tiga hal yaitu merek, kemasan itu sendiri dan label. Ada tiga alasan utama untuk melakukan pembungkusan sebagai berikut :

1. Kemasan memenuhi syarat keamanan dan kemanfaatan. Kemasan melindungi produk dalam perjalanannya dari produsen ke konsumen. Produk-produk yang dikemas biasanya lebih bersih, menarik dan tahan terhadap kerusakan yang disebabkan oleh cuaca.

2. Kemasan dapat melaksanakan program pemasaran. Melalui kemasan identifikasi produk menjadi lebih efektif dan dengan sendirinya mencegah pertukaran oleh produk pesaing. Kemasan merupakan satu-satunya cara perusahaan membedakan produknya.

3. Kemasan merupakan suatu cara untuk menghubungkan produsen dengan konsumen (aspek komunikasi termasuk di dalamnya meningkatkan laba perusahaan). Oleh karena itu, perusahaan harus membuat kemasan semenarik mungkin. Dengan kemasan yang sangat menarik diharapkan dapat memikat dan menarik perhatian konsumen. Selain itu juga, kemasan juga dapat mengurangi kemungkinan kerusakan barang dan kemudahan dalam pengiriman. (Junaidi, 2009) 


\section{c. Cenderamata}

Cenderamata adalah sesuatu yang dibawa wisatawan ke rumahnya untuk kenangan yang terkait dengan benda itu. Cenderamata bisa berarti souvenir, tanda mata, oleholeh, kenang-kenangan, atau buah tangan. Souvenir atau cenderamata membuat ingatan seseorang tentang tempat yang pernah dikunjungi. (http://jatimpos.co/id/, Diakses 03-04-2018).

Tabel 1. Berikut beberapa jenis produk cenderamata khas Kalimantan Timur

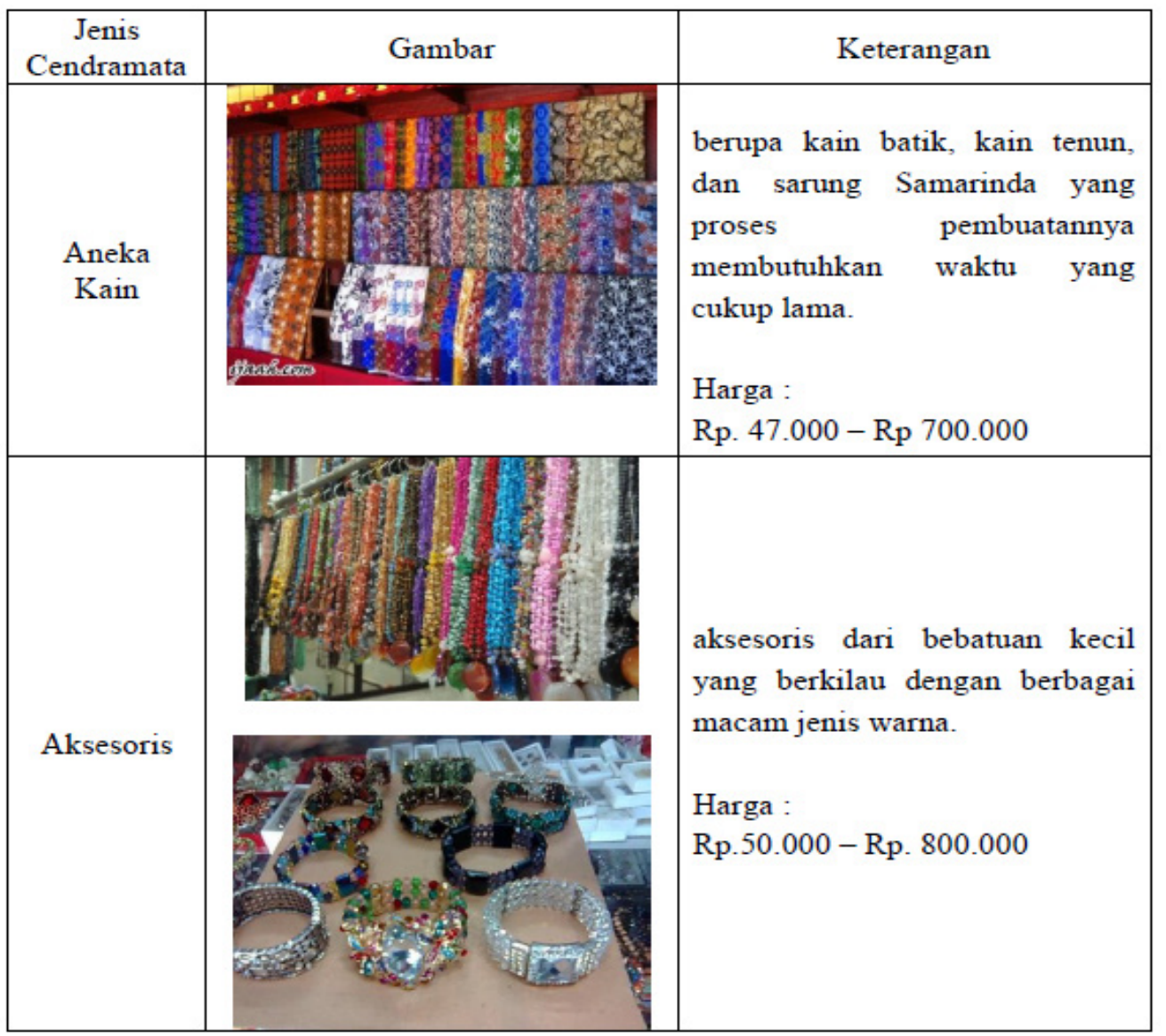

\section{d. Warna}

Sadjiman Ebdi Sanyoto (2009) mengemukakan warna dapat didefinisikan secara objektif atau fisik sebagai sifat cahaya yang dipancarkan, atau secara subjektif atau psikologis sebagai bagian dari pengalaman indra penglihatan. Secara objektif atau fisik, warna dapat diperikan oleh panjang gelom- bang. Sedangkan Pewarna non alami adalah bahan pewarna yang dibuat secara kimia oleh pabrik industri kimia. Pewarna ini biasanya dijual di pasaran dengan tanda khusus pada label atau kemasannya. 
Dyan Asdar Nursapitri Dewi, Moch Junaidi Hidayat, Pemanfaatan Limbah Kayu Untuk Kemasan Cenderamata Khas Kalimantan Timur

\section{PEMBAHASAN}

\section{a. Proses Eksperimen}

Peneliti menggunakan limbah kayu dari sisa hasil produksi industri mebel maupun pengrajin dengan jenis kayu Jati Belanda untuk proses eksperimen yang akan diterapkan pada Kemasan Cenderamata Khas Kalimantan Timur. Proses yang dilakukan adalah

pemilahan jenis limbah, pembentukan pola, pemotongan, penghalusan, penggabungan pola atau joining, proses pengukiran, mix material, dan finishing. Berikut adalah gambar mapping eksperimen yang akan dilakukan pada penelitian ini :

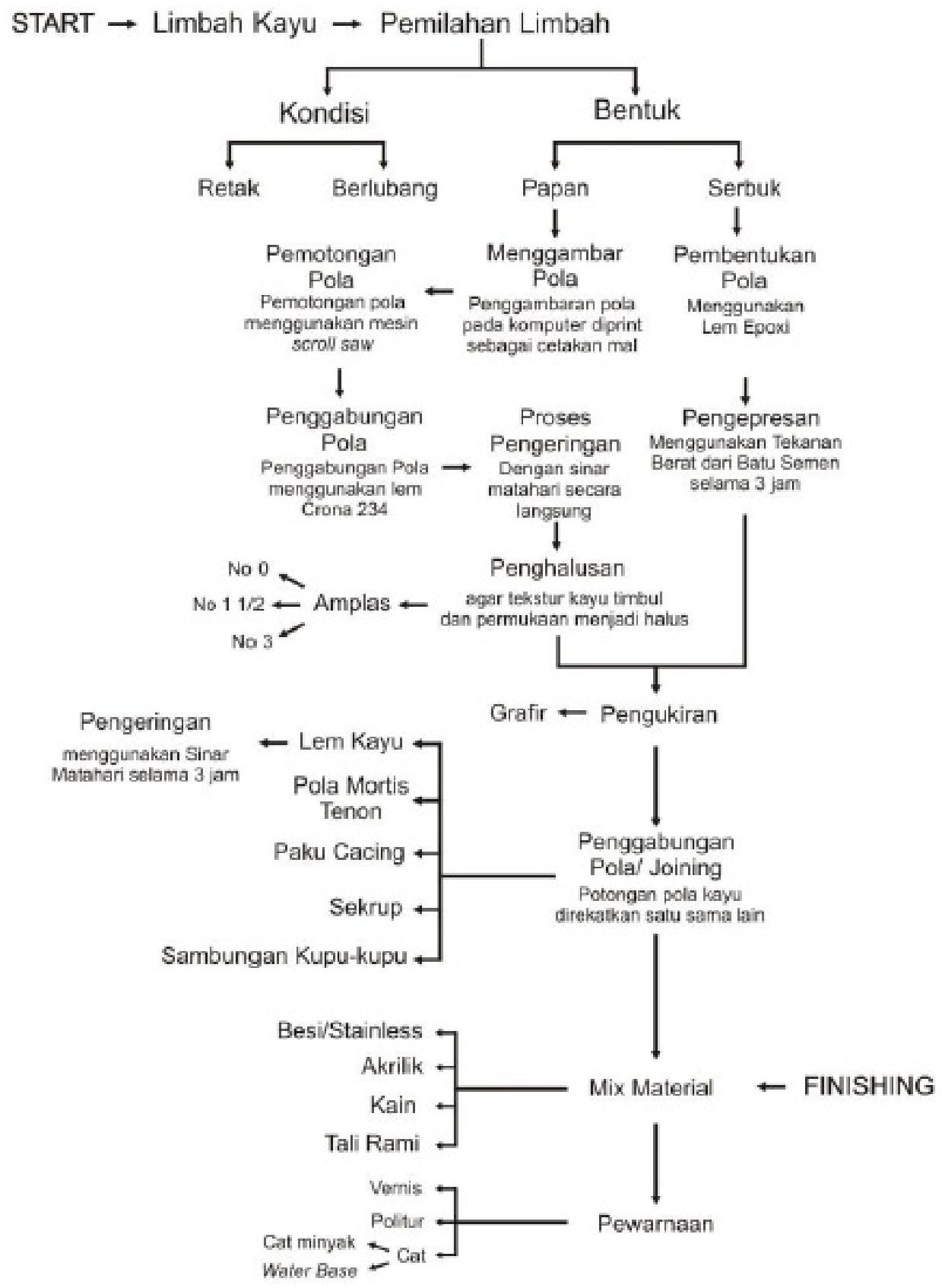

Gambar 6. Proses Desain 
Vol. 6, No. 2, April 2019

Tabel 2. Tahapan desain

\begin{tabular}{|c|c|c|c|}
\hline No & Tahapan & Gambar & Keterangan \\
\hline 1 & $\begin{array}{l}\text { Pemilahan } \\
\text { Kondisi }\end{array}$ & 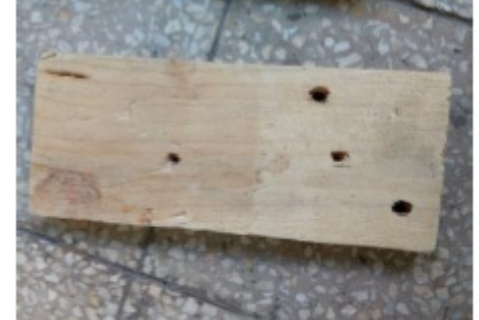 & $\begin{array}{l}\text { Kondisi limbah kayu Jati } \\
\text { Belanda pada umumnya } \\
\text { memiliki banyak bekas paku, } \\
\text { biasanya masih dapat } \\
\text { digunakan akan tetapi pada } \\
\text { proses finishing ditutupi } \\
\text { dengan dempul atau serbuk } \\
\text { kayu }\end{array}$ \\
\hline 2 & $\begin{array}{c}\text { Pemilahan Jenis } \\
\text { Limbah }\end{array}$ & $\sqrt{2}$ & $\begin{array}{l}\text { Limbah papan kayu Jati } \\
\text { Belanda rata-rata memiliki } \\
\text { ketebalan } 1 \mathrm{~cm}-2 \mathrm{~cm} \text {, } \\
\text { kebanyakan sisa potongan } \\
\text { berbentuk persegi panjang } \\
\text { dengan ukuran lebar } \\
\text { berbagai macam walaupun } \\
\text { banyak sisa potongan papan } \\
\text { yang tidak beraturan }\end{array}$ \\
\hline 3 & $\begin{array}{l}\text { Pembentukan } \\
\text { Pola }\end{array}$ & 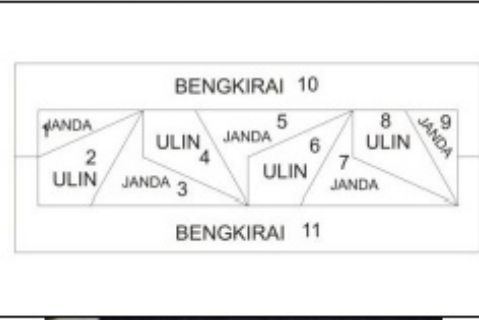 & $\begin{array}{l}\text { Proses penggambaran pola } \\
\text { pada komputer kemudian di } \\
\text { print pada kertas HVS } \\
\text { selanjutnya setiap pola } \\
\text { digunting dan ditempel } \\
\text { menggunakan double tape } \\
\text { pada kayu yang ingin } \\
\text { dipotong }\end{array}$ \\
\hline 4 & Penghalusan & $\begin{array}{c}\text { Karakteristik : Permukaan amplas } \\
\text { halus dan tipis }\end{array}$ & $\begin{array}{l}\text { Permukaan halus tidak ada } \\
\text { serat kayu yang keluar } \\
\text { membutuhkan sedikit tenaga } \\
\text { dan waktu yang cukup lama } \\
\text { saat proses penghalusan. }\end{array}$ \\
\hline 5 & Pengukiran & Grafir pada kayu Jati Belanda & $\begin{array}{l}\text { Pengukiran pada permukaan } \\
\text { kayu Jati Belanda dengan } \\
\text { pola outline motif Dayak. }\end{array}$ \\
\hline
\end{tabular}


Dyan Asdar Nursapitri Dewi, Moch Junaidi Hidayat, Pemanfaatan Limbah Kayu Untuk Kemasan Cenderamata Khas Kalimantan Timur

\begin{tabular}{|c|c|c|l|}
\hline 6 & $\begin{array}{c}\text { Penggabungan } \\
\text { Pola }\end{array}$ & $\begin{array}{l}\text { Sambungan kupu-kupu yaitu } \\
\text { sambungan dari kayu yang } \\
\text { dibentuk seperti pola kupu- } \\
\text { kupu kemudian pada bagian } \\
\text { papan yang ingin disatukan } \\
\text { dipahat masing-masing } \\
\text { sisinya dan pola sambungan } \\
\text { tersebut. }\end{array}$ \\
\hline 7 & Mix Material & Sambungan Kupu-kupu & \\
\hline 8 & Pewarnaan & $\begin{array}{l}\text { Akrilik yang telah dipotong } \\
\text { dengan ukuran tertentu } \\
\text { rekatkan pada kayu Jati } \\
\text { Belanda }\end{array}$ \\
\hline & Cat Waterbase & $\begin{array}{l}\text { Untuk yang berwarna bagian } \\
\text { pertama dan kedua dari } \\
\text { sebelah kiri tekstur terlihat } \\
\text { tetapi bukan warna alami } \\
\text { kayu dan transparansi } \\
\text { Glossy permukaan } \\
\text { mengkilap, warna kayu } \\
\text { alami dan tekstur kayu } \\
\text { terlihat lebih tegas. }\end{array}$ \\
\hline
\end{tabular}

Dari proses eksperimen yang dilakukan didapatkan sintesa eksperimen sebagai berikut :

1. Proses pemilahan bahan yang dilakukan agar mendapatkan bahan yang kondisinya masih dapat digunakan yang tidak lapuk, retak maupun pecah

2. Pembentukan pola yang nantinya akan dipotong menggunakan scroll saw agar mempermudah pada proses pembentukan pola dan menghemat waktu.

3. Proses penghalusan dilakukan menggunakan amplas halus nomor 0 secara manual agar tidak merusak tekstur kayu Jati Belanda.

4. Proses pembentukan pola serbuk kayu yang dicetak sesuai pola yang diinginkan menggunakan duplek.

5. Proses pengukiran ornamen dilakukan dengan sistem grafir yang hanya diterapkan pada material kayu dan akrilik.

6. Proses penggabungan pola dilakukan dengan menggunakan lem kayu dan penggabungan pola mortis tenon, karena mempermudah penggabungan pola skala kecil.

7. Proses mix material yang digunakan yaitu menggunakan akrilik

8. Pada proses pewarnaan untuk tetap mempertahankan tekstur alami yang ada pada kayu Jati Belanda yaitu menggunakan finishing water based

\section{Konsep Desain}

Konsep desain yang diaplikasikan pada produk kemasan cenderamata khas Kalimantan Timur adalah Etnik Simplicity. Dalam Kamus Besar Bahasa Indonesia Etnik adalah kedudukan tertentu karena keturunan, adat, agama, bahasa, dsb. Dan Simplicity artinya simpel lebih cenderung terkesan eksklusif sesuai dengan citra yang ingin ditonjolkan pada kemasan produk tersebut. (Chrisnawati, dkk, 2013). 
Vol. 6, No. 2, April 2019

Sehingga yang dimaksud gaya Etnik Simplicity berarti memadukan unsur budaya yang terkesan simpel dan eksklusif dengan tampilan visual sesuai gaya etnik yang dipilih.

\section{Alternatif Desain Kemasan a. Kemasan Kalung}

Desain kemasan kalung ini menggunakan pola segitiga siku-siku yang terdapat pada bagian sisi kanan dan kiri kemasan yang menggabungkan 2 jenis kayu yang saling berselingan, dan terdapat akrilik yang berbentuk segitiga agar produk kalung yang ada didalam kemasan dapat terlihat selagi kemasan tertutup.

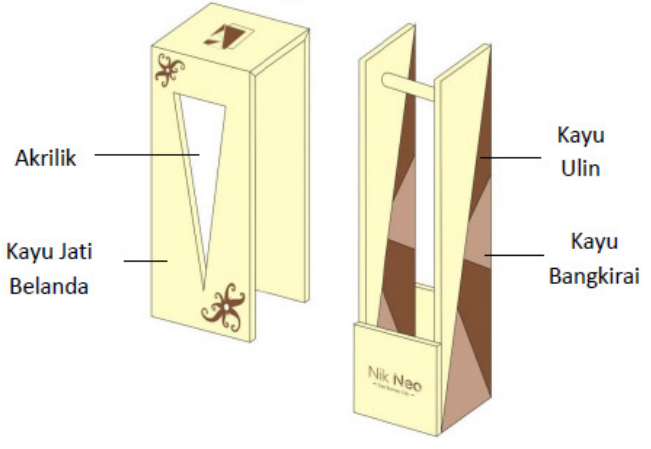

Gambar 7. Desain kemasan kalung 1
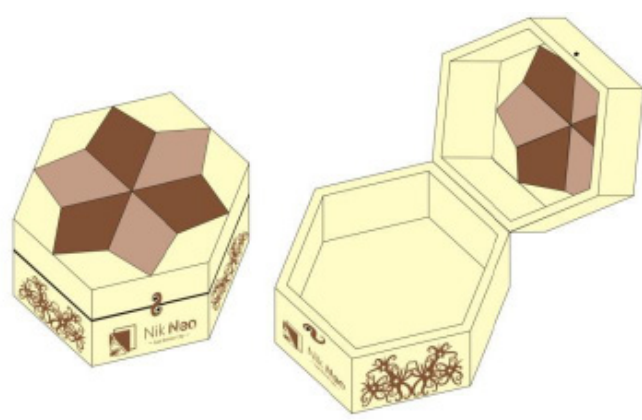

Gambar 8. Desain Kalung 2

\section{b. Kemasan Gelang}

Desain kemasan gelang khas Kalimantan dengan bentuk segi enam, potongan pola yang terdapat pada bagian penutup dengan bentuk bintang segi enam, penggabungan pola tersebut menggunakan 2 jenis material kayu.

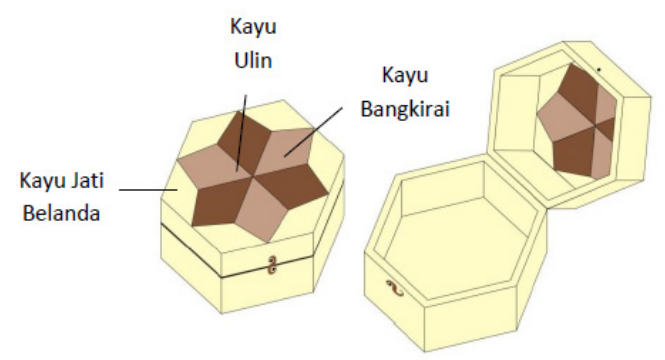

Gambar 9. Desain kemasan gelang 1
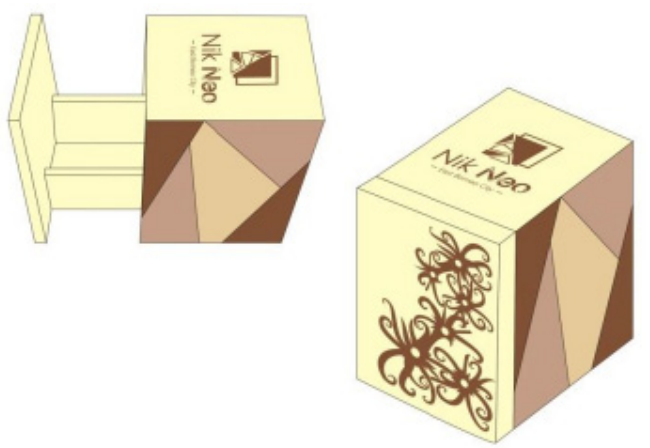

Gambar 10. Desain kemasan gelang 2

\section{c. Kemasan Cincin}

Desain kemasan cincin khas Kalimantan ini menggunakan bentuk persegi panjang yang tampak seperti terpotong, dan bagian yang terbuka akan membentuk segitiga siku-siku. dan potongan pola segitiga tak beraturan dan terdapat pada 2 sisi kemasan yang sebagai penutup kemasan tersebut, penggabungan pola tersebut menggunakan 3 jenis material kayu. 
Dyan Asdar Nursapitri Dewi, Moch Junaidi Hidayat, Pemanfaatan Limbah Kayu Untuk Kemasan Cenderamata Khas Kalimantan Timur

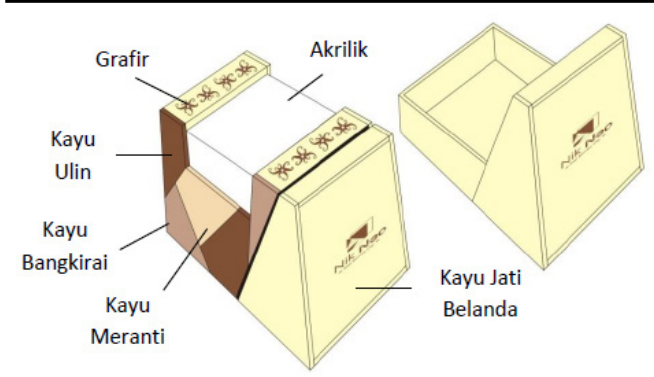

Gambar 11. Desain kemasan cincin 1

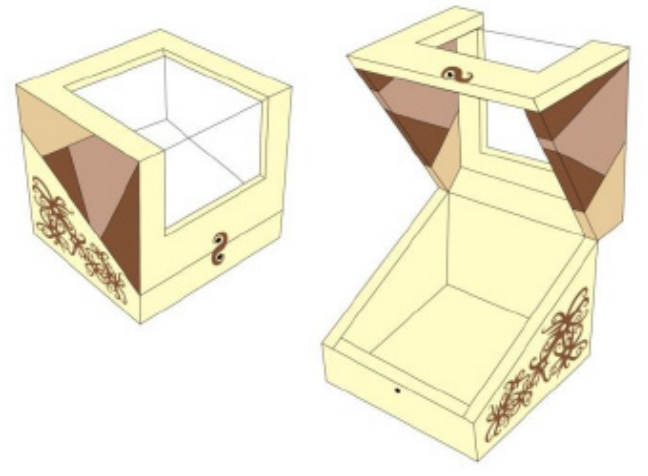

Gambar 12. Desain kemasan cincin 2

\section{d. Kemasan Kain}

Desain kemasan kain khas Kalimantan ini menggunakan bentuk dan potongan pola segi enam dengan potongan pola yang terdapat pada 3 bagian sisi yang berselingan, penggabungan pola dengan 2 jenis material kayu yang pada setiap potongan pola segi enamnya terdapat ukiran Dayak khas Kalimantan.

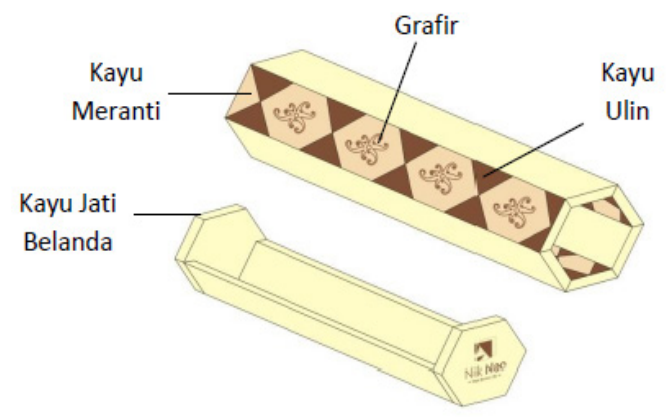

Gambar 13. Desain kemasan kain 1
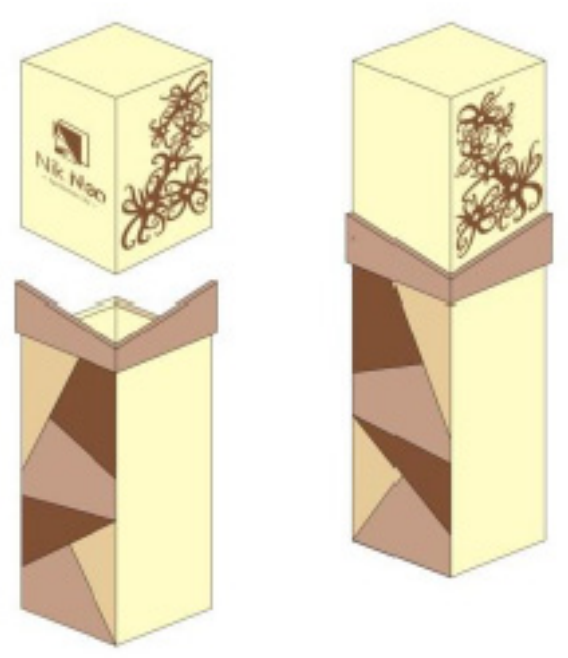

Gambar 14. Desain kemasan kain 2

\section{e. Kemasan Sarung}

Desain kemasan sarung khas Kalimantan ini menggunakan bentuk persegi panjang yang jika dibuka terbagi menjadi dua dengan bentuk segitiga siku-siku dan potongan pola segitiga tak beraturan yang terdapat pada 2 sisi kemasan yang saling bersebrangan, penggabungan pola tersebut menggunakan 3 jenis material kayu.

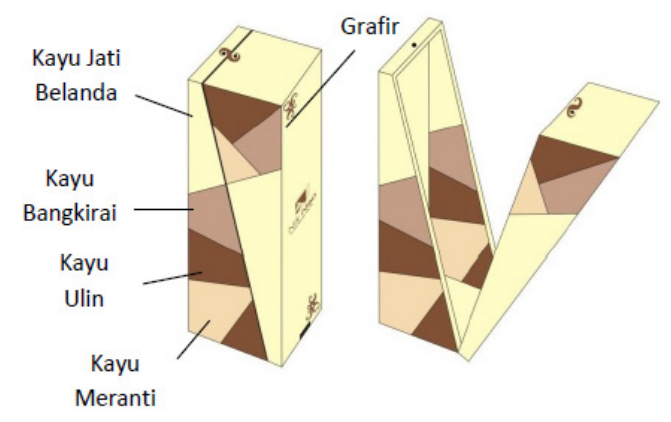

Gambar 15. Desain Kemasan Sarung 1 


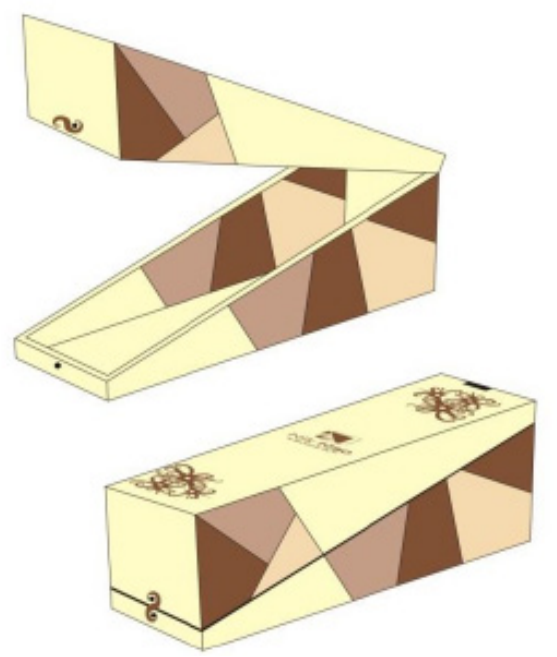

Gambar 16. Desain kemasan sarung 2

\section{Prototype Kemasan}

Berikut adalah prototype kemasan terpilih :

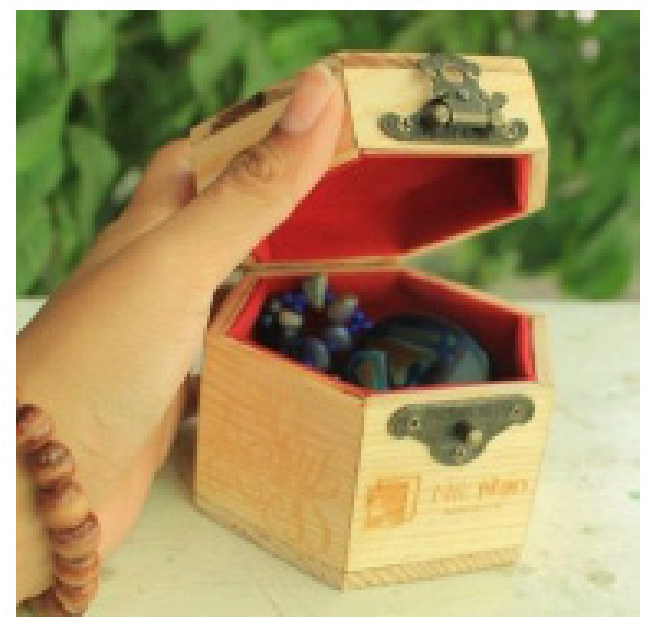

Gambar 17. Kemasan kalung

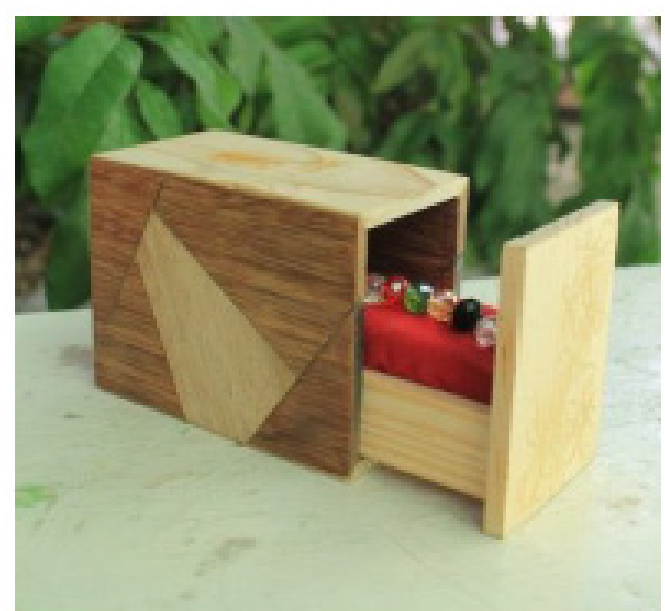

Gambar 18. Kemasan gelang

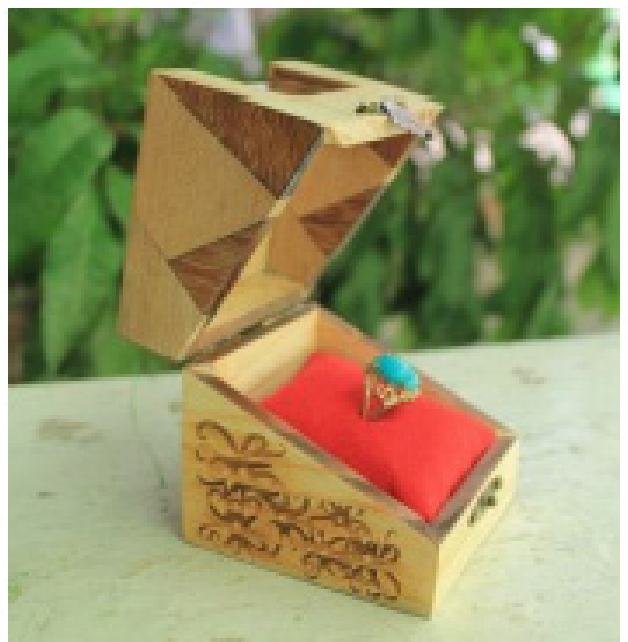

Gambar 19. Kemasan cincin

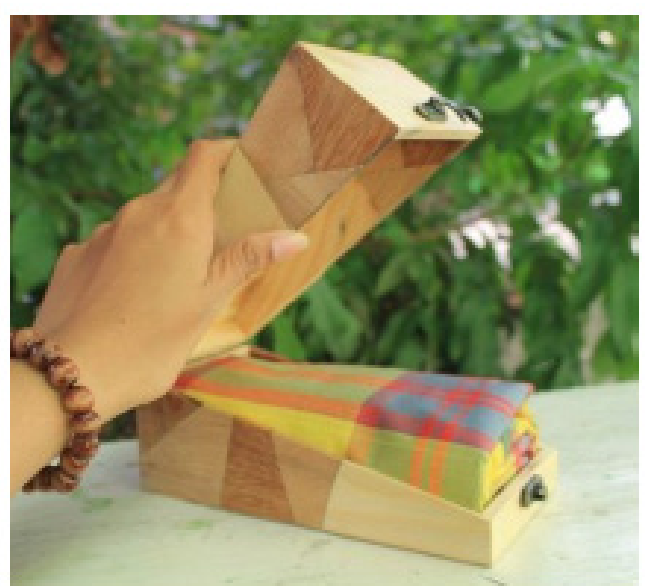

Gambar 20. Kemasan kain

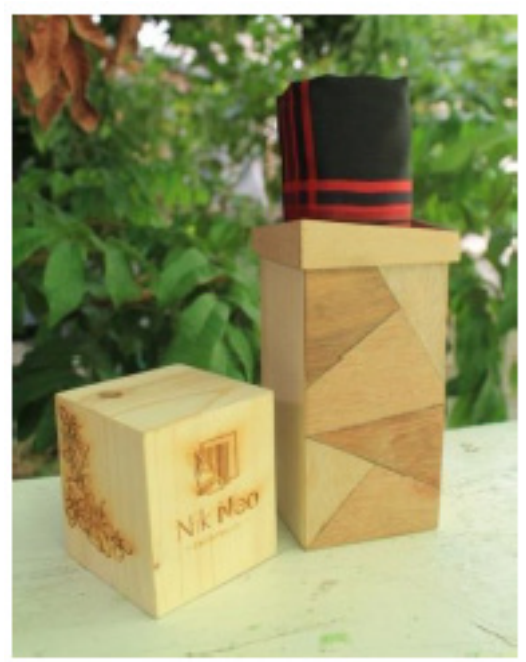

Gambar 21. Kemasan sarung 


\section{KESIMPULAN DAN SARAN}

\section{a. Kesimpulan}

Mendesain kemasan yang menggunakan bahan utama yaitu limbah sisa potongan kayu jenis limbah kayu Jati Belanda yang dipadukan dengan jenis limbah kayu khas Kalimantan yaitu Ulin, Bangkirai dan Meranti.

Terdapat 2 alternatif produksi yaitu dengan teknik manual menggunakan mesin scroll saw ada pula menggunakan mesin cutting laser.

Penambahan ukiran khas suku Dayak Kalimantan Timur menjadikan produk kemasan tersebut memiliki keunikan tersendiri yang mampu meningkatkan daya saing pada produk.

Dari hasil proses produksi pemanfaatan limbah yang telah mencapai $75 \%$ dan kembali menghasilkan 25\% limbah sisa potongan-potongan kecil, yang mana untuk memaparkan dibutuhkan eksperimen lanju$\tan$.

\section{b. Saran}

Pada proses produksi sebaiknya dilakukan dalam jumlah banyak agar bahan dan proses pembuatannya tidak terbilang mahal.

Penempatan ukiran sebaiknya disesuaikan lagi agar tidak berbenturan dengan perbaduan pola berbagai jenis kayu yang disatukan.

Perlu diperhitungkan kesiapan teknologi dan SDM untuk proses pembuatan kemasan.

Alternatif produksi kemasan padat karya, yang dilakukan oleh banyak orang sehingga biaya produksi relatif lebih murah.

Sisa limbah yang dihasilkan dari proses produksi dengan asumsi $25 \%$ yang meliputi potongan-potongan kecil yang membutuhkan eksperimen lanjutan. 


\section{DAFTAR PUSTAKA}

Chrisnawati, Yoanita, Bedjo Riyanto dan Elisabeth Christine Yuwono, (2013), Perancangan Desain Kemasan Kerajinan Di Ria Batik Solo Sebagai Cinderamata Khas Dari Kota Solo, Jurnal Desain Komunikasi Visual Adiwarna, Universitas Sebelas Maret, Surakarta.

Hidayat, Moch. Junaidi (2009), Analisis industri budaya pada desain produk kemasan makanan Industri kecil menengah, Acintya Jurnal Penelitian Seni Budaya, Institut Seni Indonesia (ISI) Surakarta, Volume 1 No. 2 Desember 2009, Hal 141-151.

Sanyoto, Sadjiman Ebdi (2009), Nirmana Dasar-dasar Seni dan Desain, Jalasutra, Yogyakarta

http://jatimpos.co/id/en/pariwisata/681-cinderamata-sarana-kenalkan-daerah-tujuan-wisata (Akses 03 April 2018) 